\title{
MONITORING OF SURFACE DAMAGE IN RAILS AFTER LONG TERM CVCLIC LOADING
}

\begin{abstract}
This paper reports about possible concept in which surface damage of the rail after long tem cyclic loading can be executed. This study employs non destructive magnetic Barkhausen noise as a promising technique which exhibits very good sensitivity against extent of surface damage. Magnetic Barkhausen noise is correlated with the conventional parameters of surface integrity expressed in term of the thickness of damaged layer, its micro hardness as well as stress state. Furthermore, phase analysis of the real surface indicates that extensive phase transformations are produced by the repeated severe plastic deformation. Phase composition of the damaged layer indicates that structure transformation in the rail surface is thermally induced rather than deformation induced process.
\end{abstract}

Keywords: Plastic deformation, non destructive evaluation, phase transformation.

\section{Introduction}

Large axle loads of the trains usually cause serious wear and structure transformations of the rails. Near surface region of the rail surface appears white under the metallographic observation [1 - 3]. For this reason this region is named white etching layer (WEL). Origin of WEL was widely discussed. Newcomb and Stobbs reported that WEL is initiated by the repetitive and severe plastic deformation [4]. On the other hand, phase analyses reveal retained austenite which indicates that WEL is thermally initiated process when the near surface region undergoes heating above austenitizing temperature followed by rapid self - cooling [1 - 3 and 5]. Such process hinders full transformation of austenite to pearlite and certain volume of austenite retains in the WEL. WEL was subjected to many studies in which variable techniques were employed to identify stress state, phase composition, chemical and other alterations [1 - 5]. It was reported [1] that WEL is a product of rolling-contact fatigue caused by the alternating stresses associated with rolling contact bodies. Operation of the rails containing WEL regions may be risky with the respect to possible rails macro cracking initiated by micro cracks in the WEL. Furthermore, rails are subjected to grinding process in order to remove damaged layer and surface asperities [3].

For these reasons the suitable non destructive method would be beneficial to revelation of the surface damage degree. Magnetic Barkhausen noise (MBN) is sensitive to microstructure and stress state [6 - 11]. Being so, this study deals with sensitivity of MBN technique for such purpose. MBN originates from irreversible and discontinuous Bloch Walls (BW) motion during the cyclic magnetization. The main reason can be viewed in pinning strength of variable microstructure features interfering with $\mathrm{BW}$ in motion. Irreversible and discontinuous BW motion produces acoustic as well as electromagnetic pulses. Electromagnetic pulses propagate towards free surface and can be detected by the use of a suitable pick up coil. It is well known that MBN is a function of stress state as well as microstructure. However, stress state affects mainly the domain and corresponding BW alignment whereas microstructure affects the free path of BW motion [7]. Microstructure of matrix can be expressed in many terms and it is worth to mention that BW interferes with all crystalline defects. Being so, in many studies MBN is studied as a function of dislocation density [9], carbides precipitation [10], grain size or presence of non ferromagnetic phases [7]. Transformations in WEL are very complex and fully change character of the matrix. Being so, MBN could be a promising technique for monitoring of surface state of rails in operation. This pilot study reports about monitoring of surface damage in the rail by the use of MBN.

\footnotetext{
* ${ }^{1}$ Katarina Zgutova, ${ }^{2}$ Miroslav Neslusan, ${ }^{1}$ Juraj Sramek, ${ }^{1}$ Peter Danisovic, ${ }^{3}$ Jiri Capek

${ }^{1}$ Faculty of Civil Engineering, University of Zilina, Slovakia

${ }^{2}$ Faculty of Mechanical Engineering, University of Zilina, Slovakia

${ }^{3}$ Faculty of Nuclear Science and Physical Engineering, CVUT Praha, Czech Republic

E-mail: katarina.zgutova@fstav.uniza.sk
} 


\section{Experimental part}

The experimental study was carried out on hot rolled rail steel R220 (strength $785 \pm 50 \mathrm{MPa}$, hardness $215 \pm 35 \mathrm{HB}$ ) of chemical composition indicated in Table 1.

Chemical composition of the rail steel R220 in wt \%. Table 1

\begin{tabular}{|c|c|c|c|c|c|c|c|}
\hline $\mathrm{Fe}$ & $\mathrm{C}$ & $\mathrm{Mn}$ & $\mathrm{Si}$ & $\mathrm{Cr}$ & $\mathrm{Ni}$ & $\mathrm{Cu}$ & $\mathrm{P}$ \\
\hline bal. & 0.60 & 1.05 & 0.21 & 0.12 & 0.13 & 0.07 & 0.02 \\
\hline
\end{tabular}

The rail was subjected to the 20 years accumulated passing tonnage about 0.8 million tons per year. Figure 1 shows a photo of the rail profile with indication of the analyzed zone. The rail surface was measured and analyzed within the whole rail width in which the possible contact of the rail and wheel can be expected. Metallographic observation, micro hardness alterations, XRD and MBN measurements were carried in certain points regularly distributed within the rail width (distance between the neighboring points is kept $6 \mathrm{~mm}$ ).

MBN was measured by the use of RollScan 350 and software $\mu$ Scan 500 (magnetizing voltage $5 \mathrm{~V}$, magnetizing frequency $125 \mathrm{~Hz}, 10$ bursts, sensor type S1-18-12-01, frequency range of MBN from 10 to $1000 \mathrm{kHz}$ ). MBN values were obtained by averaging 10 MBN bursts (5 magnetizing cycles). MBN refers to the rms (effective) value of the signal. Estimated sensing depth of the MBN signal is about $50 \mu \mathrm{m}$. Magnetization of the rail surface was carried out in the direction of traction.

Residual stresses and phase analysis were measured via X-ray diffraction technique (XRD) (\{211\}, $\alpha$-Fe, $\mathrm{CrK} \alpha, 40 \mathrm{kV}$, $30 \mathrm{~mA}$, average sensing depth approx. $5 \mu \mathrm{m}$, X'Pert PRO). Except stress state also Full Width at Half Maximum (FWHM) was analyzed since this parameter is closely connected with micro hardness of the matrix.

To reveal the microstructure transformations induced by severe plastic deformation $10 \mathrm{~mm}$ long pieces were routinely prepared for metallographic observations (etched by $3 \%$ Nital for 8s). Microstructure was observed in the direction longitudinal with the track direction.

Vickers micro hardness readings were conducted by Zwick Roel ZHm micro-hardness tester by applying the force $50 \mathrm{~g}$ for 10 seconds. Micro hardness was determined by averaging 3 repetitive measurements ( 3 micro hardness profiles spaced $0.1 \mathrm{~mm}$ ).

All measurements were conducted at 7 points within the rail surface region indicated in Fig. 1. The first position was placed $3 \mathrm{~mm}$ from the left side. The following positions were spaced $6 \mathrm{~mm}$ each to other (also bulk structure was investigated).

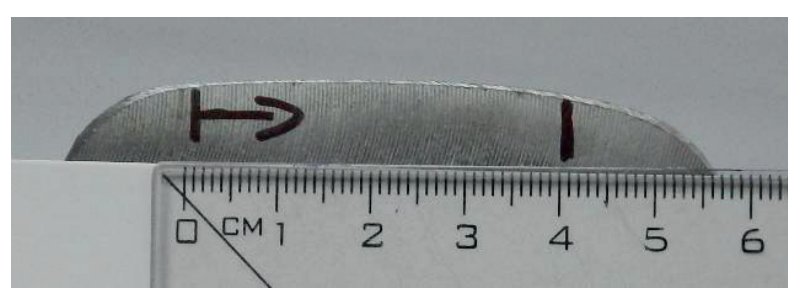

Fig. 1 The rail cross section with indication of measured width

\section{Results of experiments}

Figure 2 illustrates the bulk structure as well as rail surfaces. Bulk is composed of pearlite with the equiaxed grains. On the other hand, the sub surface regions exhibit preferential orientation of the pearlite matrix due to hot rolling process. WEL is superimposed on this preferentially oriented matrix. Figure 3 also depicts that thickness of WEL varies within the investigated rail width. Thin and discontinuous WEL can be found on the left side of the rail width (distance $3 \mathrm{~mm}$ ) whereas thick and continuous WEL is located at the distance 9 and especially $15 \mathrm{~mm}$ from the left side of the rail. Distances 21 and $27 \mathrm{~mm}$ also exhibit thin and discontinuous WEL whereas positions 33 and $39 \mathrm{~mm}$ indicate no WEL in the surface region.

It can be easily understood that the main rail load is positioned in the zones of thick and continuous WEL. Micrographs also indicate that the rail surface is polluted by the long term oxidation. Oxides initiated on the rail free surface contaminate not only WEL region but the whole rail width and process of plastic deformation dips oxides into the deeper layer beneath the free surface. Micrographs also reveal surface cracking since WEL regions become hard and brittle. Further loading of such structure together with oxidizes initiate micro cracking contributing to the remarkable irregularities in the rail surface profile.

Surface oxidation can be verified by phase analyses executed by the use of XRD technique. Table 2 indicates that all regions contain $\mathrm{Fe}_{2} \mathrm{O}_{3}$ and first 3 regions also $\mathrm{FeO}$. Table 2 also shows that bulk structure is entirely composed of pearlite phase. On the other hand, thick WEL regions contain martensite matrix of high tetragonality mixed with retained austenite whereas the right side of the rail width is composed of ferrite (low degree of lattice tetragonality) without retained austenite. Phase analysis verifies that WEL is thermally induced structure since retained austenite indicates that the near surface region undergoes heating above the austenitizing temperature. Table 2 also indicates that original pearlite structure is completely decomposed. Cementite lamellas are broken into very fine particles and certain volume of carbon is dissolved in the matrix [2 and 5]. 


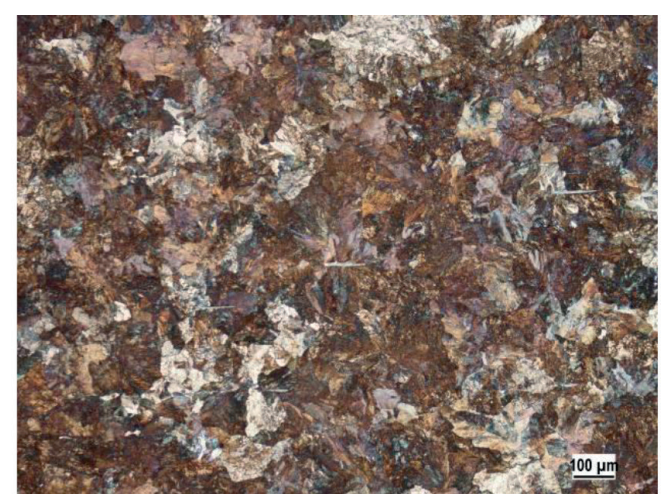

a) bulk

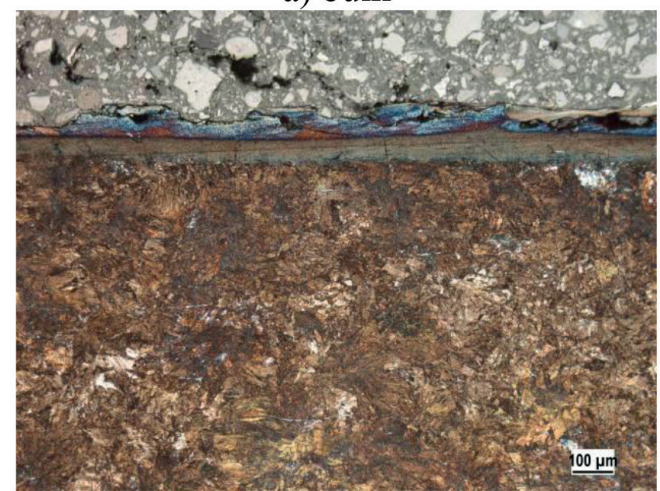

c) distance $9 \mathrm{~mm}$

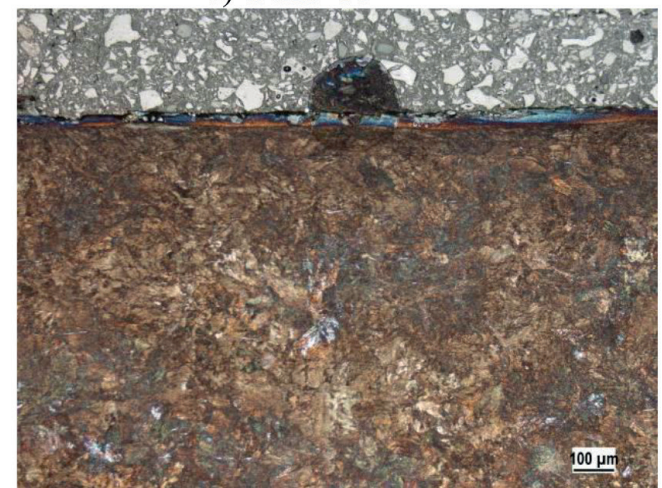

e) distance $21 \mathrm{~mm}$

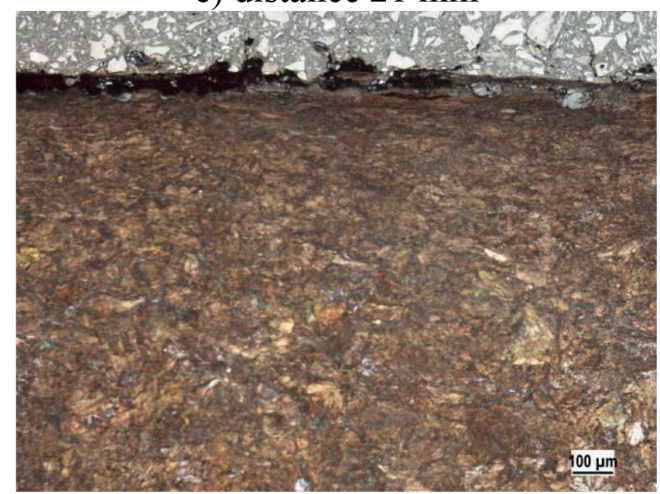

g) distance $33 \mathrm{~mm}$

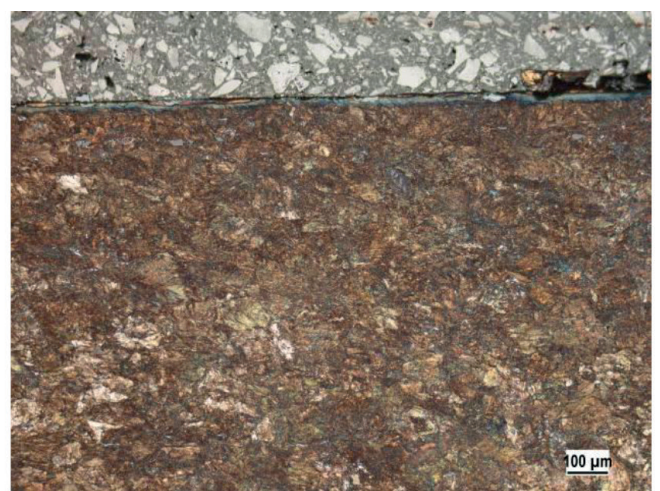

b) distance $3 \mathrm{~mm}$

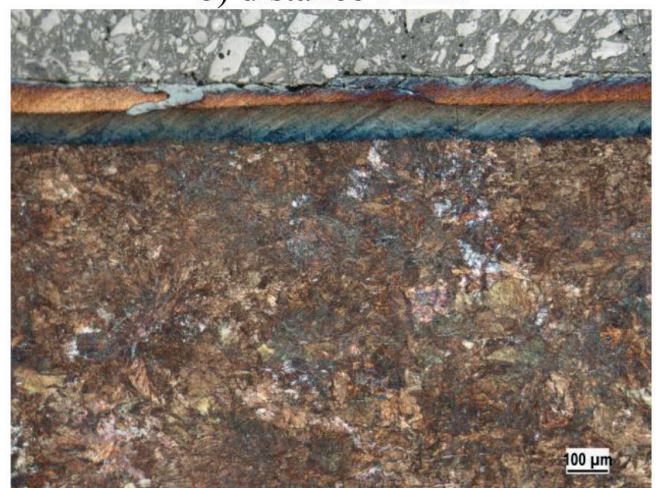

d) distance $15 \mathrm{~mm}$

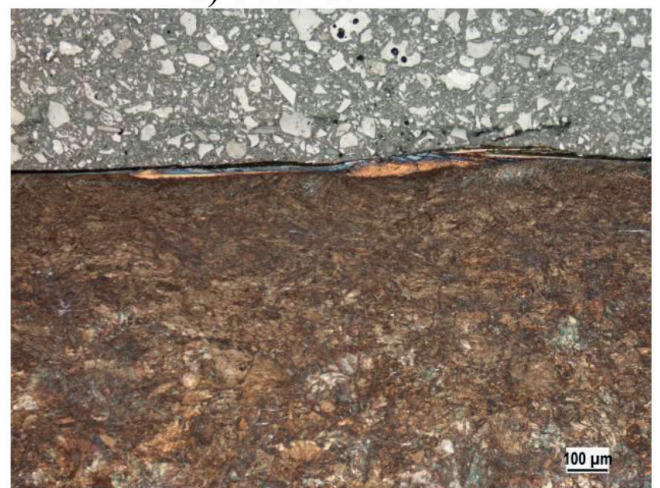

f) distance $27 \mathrm{~mm}$

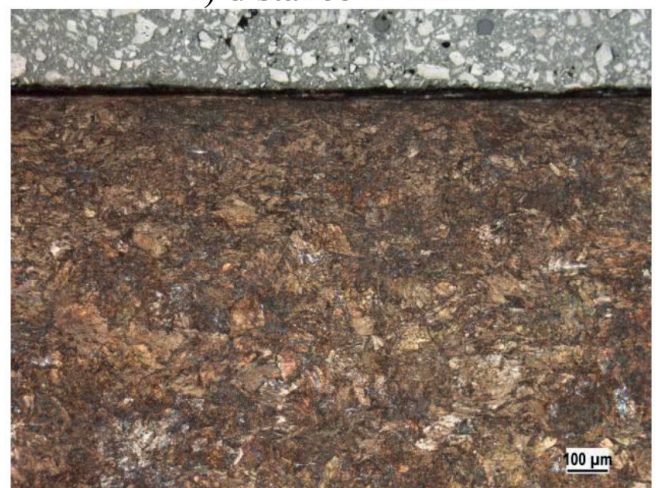

h) distance $39 \mathrm{~mm}$

Fig. 2 Metallographic observation of the rail surface + bulk 
Phases on the rail surface indicated by XRD technique

Table 2

\begin{tabular}{|c|c|c|c|c|c|c|c|}
\hline $\begin{array}{c}\text { dis. } \\
(\mathrm{mm})\end{array}$ & $\mathrm{Fe}$ & $\mathrm{Fe}$ & $\mathrm{Fe}_{3} \mathrm{C}$ & $\mathrm{Fe}_{2} \mathrm{O}_{3}$ & $\mathrm{FeO}$ & $\mathrm{C}$ & $\mathrm{Fe}$ fct \\
\hline 3 & - & $\bullet$ & - & $\bullet$ & $\bullet$ & $\bullet$ & $\bullet^{+}$ \\
\hline 9 & - & $\bullet$ & - & $\bullet$ & $\bullet$ & $\bullet$ & $\bullet^{+}$ \\
\hline 15 & - & $\bullet$ & - & $\bullet$ & $\bullet$ & $\bullet$ & $\bullet$ \\
\hline 21 & - & - & - & $\bullet$ & - & $\bullet$ & $\bullet$ \\
\hline 27 & - & - & - & $\bullet$ & - & $\bullet$ & $\bullet$ \\
\hline 33 & - & - & - & $\bullet$ & - & $\bullet$ & $\bullet$ \\
\hline 39 & - & - & - & $\bullet$ & - & $\bullet$ & $\bullet$ \\
\hline bulk & $\bullet$ & - & $\bullet$ & - & - & - & - \\
\hline
\end{tabular}

+ - high degree of lattice tetragonality

- - low degree of lattice tetragonality
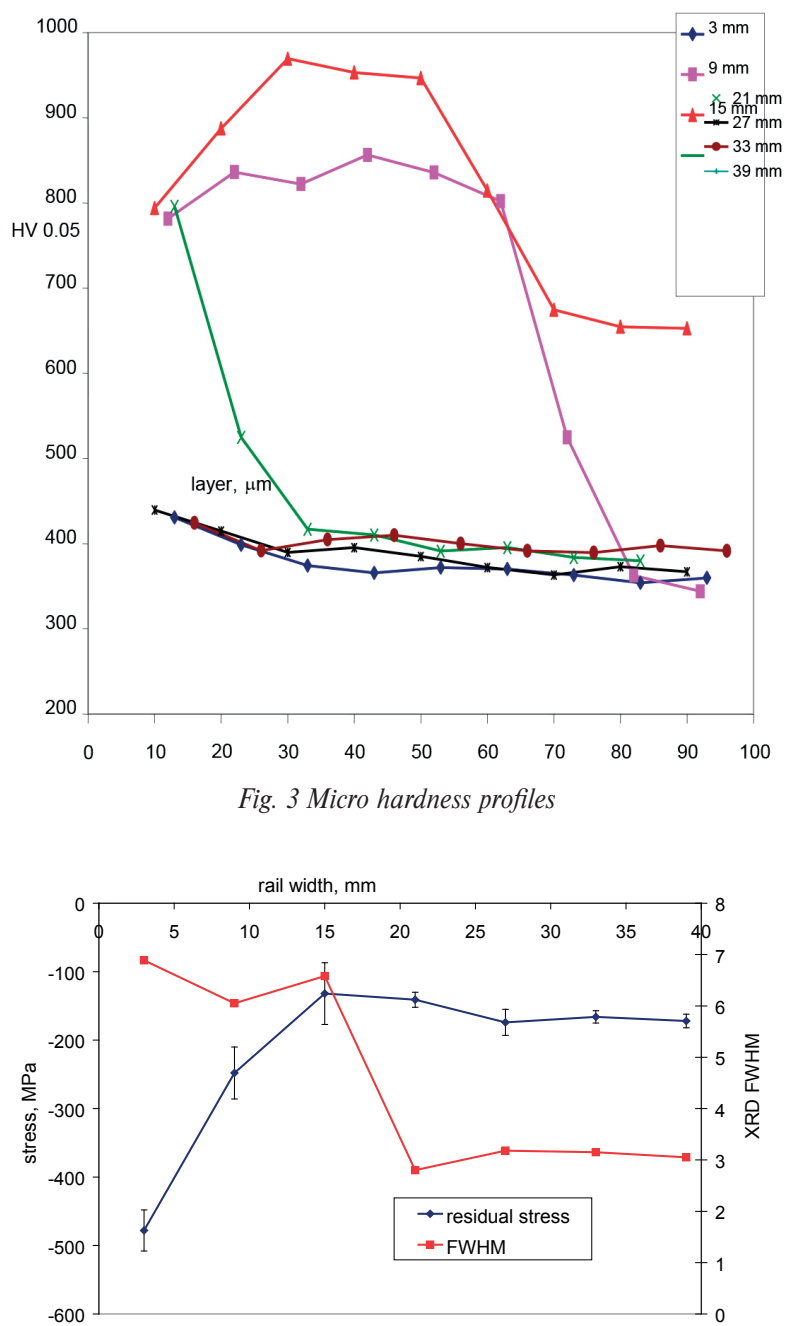

Fig. 4 Residual stresses and FWHM (XRD)
High hardness of the WEL corresponds with the high tetragonality of matrix (see Table 2) and associated dislocation density. Such matrix is produced due to rapid self - cooling from austenitizing temperature and results into remarkable surface hardening [1 - 2 and 5]. Thick and continuous WEL corresponds with quite deep extent of high hardness for distances 9 and especially $15 \mathrm{~mm}$. On the other hand, it is worth to mention that micro hardness profiles for distances 3,21 and $27 \mathrm{~mm}$ are debatable since WELs in these areas are discontinuous; they can occur in the form of localized spots thus indentation results can remarkably vary in the near surface region.

As it was expected, compressive stresses can be found within the whole rail width. The left side exhibits higher magnitude of compressive stresses compared to the rest of the rail surface. Figure 4, Table 3 and Fig. 5 show poor sensitivity of residual stresses against the thickness of WEL since the thick WEL gives nearly the same stresses as the regions containing thin discontinuous WEL or regions free of WEL, see Fig. 4. The main reasons can be found as follows:

sensing depth of XRD technique is too low (about $5 \mu \mathrm{m}$ ) compared with thickness of WEL; thus stress state can not distinguish between thin and thick WEL,

surface cracking releases the stresses in the WEL and other regions,

due to long term cyclic loading WEL region undergoes repetitive periods of surface hardening followed by the matrix dynamic recovery and the corresponding stress relaxation [2].

On the other hand, FWHM is more sensitive to the structure alterations; thus regions containing thick WEL exhibit high values of FWHM a vice versa, see Fig. 4, Table 2 and Fig. 6. High values of FWHM correspond with high hardness and associated high dislocation density. Compared to the stress state, relationship between WEL thickness and FWHM exhibits better correlation (expressed in term $\mathrm{R}^{2}$ ), see Fig. 6. 
MBN (rms) and thickness of WEL

Table 3

\begin{tabular}{|c|c|c|c|c|c|c|c|}
\hline & $3 \mathrm{~mm}$ & $9 \mathrm{~mm}$ & $15 \mathrm{~mm}$ & $21 \mathrm{~mm}$ & $27 \mathrm{~mm}$ & $33 \mathrm{~mm}$ & $39 \mathrm{~mm}$ \\
\hline MBN, $\mathrm{mV}$ & $389 \pm 8$ & $223 \pm 8$ & $144 \pm 15$ & $390 \pm 15$ & $334 \pm 12$ & $303 \pm 9$ & $315 \pm 14$ \\
\hline WEL, $\mu \mathrm{m}$ & $29 \pm 29$ & $111 \pm 22$ & $152 \pm 55$ & $22 \pm 22$ & $44 \pm 44$ & 0 \\
\hline
\end{tabular}

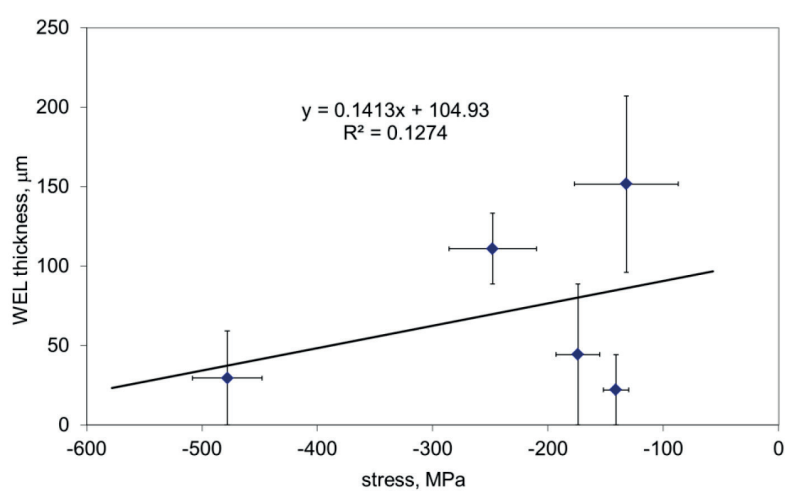

Fig. 5 Residual stresses versus WEL thickness

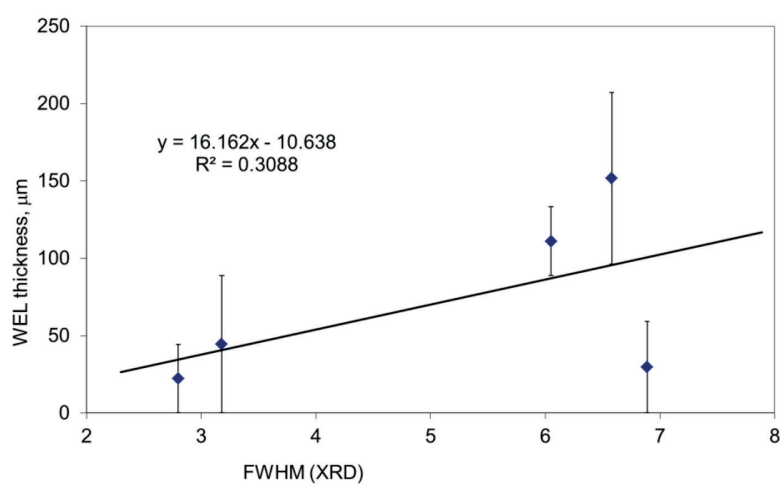

Fig. 6 FWHM versus WEL thickness

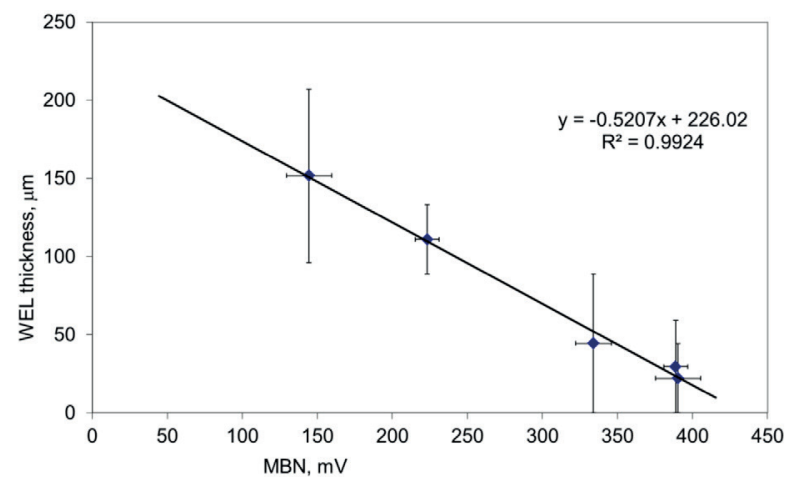

Fig. 7 MBN versus WEL thickness
Table 2 and Fig. 7 show very good sensitivity of MBN versus WEL thickness. Relation between MBN and WEL thickness is linear and increasing WEL thickness can be directly linked with decreasing magnitude of $\mathrm{MBN}$ signal. The main reasons can be found as follows:

- much higher sensing depth of MBN technique (compared with XRD technique),

martensite matrix of the high degree of lattice tetragonality containing carbon in the supersaturated state, high dislocation density and the corresponding high hardness,

retained austenite in the WEL strongly hinder BW motion,

oxides $\left(\mathrm{FeO}\right.$ and $\mathrm{Fe}_{2} \mathrm{O}_{3}$ ) as hard ferromagnetic particles embedded in the martensite matrix also strongly pin BW motion,

micro cracks such as defects not producing MBN emission.

Figure 7 shows that thickness of WEL can be easily obtained from MBN signal; thus damaged rail layer can be monitored in a non destructive manner.

\section{Conclusions}

Micro cracking in the hard and brittle WEL arises from the cyclic long term loading and potentially can initiate rail macro cracking. For this reason, rails should be subjected to the re-grinding process in order to remove the damaged layer and refresh the surface state. MBN technique could be potentially employed for the assessment of WEL thickness as a layer removed by grinding. Finally, this is the pilot study which would suggest a possible concept for prevention of unexpected rails deformation (or cracking) due to their thermal dilatation (and the corresponding stresses) initiated by the ambient temperature fluctuations via MBN technique. However, MBN emission initiated by external stresses is combined with MBN from the accumulated damage of the rail surface due to its cyclic severe loading.

\section{Acknowledgement}

This work was supported by the VEGA project No. 1/0254/15 and project: University Science Park of the University of Zilina (ITMS: 26220220184). 


\section{References}

[1] PAL, S., DANIEL, J. T., VALENTE, H. G., WILSON, A., ATRENS, A.: Surface Damage on New AS60 Rail Caused by Wheel Slip, Engineering Failure Analysis, 22, 2012, 152-165.

[2] TAKAHASHI, J., KAWAKAMI, K., UEDA, M..: Atom Probe Tomography Analysis of the White Etching Layer in a Rail Track Surface, Acta Materialia, 58, 2010, 3602-3612.

[3] SANTA, J. F., TORO, A., LEWIS, R.: Correlation between Rail Wear Rates and Operating Conditions in a Commercial Railroad, Tribology International, 95, 2016, 5-12.

[4] NEWCOMB, S. B., STOBBS, W. M.: A Transmission Electron Microscopy Study of the White-Etching Layer on a Rail Head, Materials and Science Engineering Materials and Engineering, 66, 1984, 195-204.

[5] WANG, L., PYZALlA, A., STADLBAUER, W., WENER, E. A.: Microstructure Features on Rolling Surfaces of Railways Rails Subjected to Heavy Loading, Materials and Science Engineering Materials and Engineering, A 359, 2003, 31-43.

[6] KARPUSCHEWSKI, B., BLEICHER, O., BEUTNER, M.: Surface Integrity Inspection on Gears Using Barkhausen Noise Analysis. Processing Engineering, 19, 2011, 162-171.

[7] MOORTHY, V., SHAW, B. A., MOUNTFORD, P., HOPKINS, P.: Magnetic Barkhausen Noise Emission Technique for Evaluation of Residual Stress Alteration by Grinding in Case - Carburized En36 Steel, Acta Materialia, 53, 19, $2005,4997$. 5006.

[8] GATEliER-ROTHEA, C., CHICOIS, J., FOUGERES, R., FLEISCHMANN, P.: Characterization of Pure Iron and (130 p.p.m.) Carbon-iron Binary Alloy by Barkhausen Noise Measurements: Study of the Influence of Stress and Microstructure. Acta Metallurgica, 46, 14, 1998, pp. 4873-4882.

[9] CIZEK, J., NESLUSAN, M., CILliKOVA, M., MICIETOVA, A., MELIKHOVA, O.: Modification of Steel Surfaces Induced by Turning: Non-Destructive Characterization Using Barkhausen Noise and Positron Annihilation, J. of Physics D, Applied Physics, 47, 2014, 1-17.

[10] NESLUSAN, M., CIZEK, J., KOLARIK, K., MINARIK, P., CILLIKOVA, M., MELIKOVA, O.: Monitoring of Grinding Burn via Barkhausen Noise Emission in Case-Hardened Steel in Large-Bearing Production, J. of Materials Processing Technology, vol. 240, 2017, 104-117.

[11] PITONAK, M., CANGAR, M.: Non-Destructive Testing of Settling Tank, Advances and Trends in Engineering Sciences and Technologies, Proc. of the Intern. Conference on Engineering Sciences and Technologies, ESaT 2015, 353-358. 